\title{
Clinical and biological significance of erlotinib therapy after pemetrexed in non-small cell lung cancer with wild-type EGFR
}

\author{
N. KOYAMA ${ }^{1,2, *}$, M. SUZUKI ${ }^{2}$ \\ ${ }^{1}$ Division of Pulmonary Medicine, Clinical Department of Internal Medicine, Jichi Medical University Saitama Medical Center, Saitama-shi, \\ Saitama, Japan; ${ }^{2}$ Department of Respiratory Medicine, Saitama Medical University International Medical Center, Hidaka-shi, Saitama, 350- \\ 1298, Japan \\ *Correspondence: nkoyama@jichi.ac.jp
}

Received May 7, 2015 / Accepted July 27, 2015

\begin{abstract}
Pemetrexed is a multi-targeted anti-folate agent that confers favorable benefits to patients with non-small cell lung cancer (NSCLC). However, the optimal use including treatment schedule of pemetrexed and other drugs in clinical practice remains to be determined, particularly for NSCLC with wild-type epidermal growth factor receptor (EGFR). The present study investigated a potential therapeutic strategy for NSCLC patients with wild-type EGFR who were treated with pemetrexed. To identify factors associated with a survival, medical record data from 130 patients were retrospectively reviewed, using the KaplanMeier method with log-rank test. Factors identified in the clinical analysis were further investigated within in vitro studies. Patients who underwent the treatment schedule of erlotinib at the time of progression after pemetrexed-based chemotherapy prolonged overall survival, compared to those treated with other schedules ( $p=0.010$; hazard ratio, 0.418 ). This survival benefit was also observed in the treatment schedule of pemetrexed monotherapy and subsequent erlotinib $(p=0.008$; hazard ratio, 0.220 ). As a treatment at the time of progression after pemetrexed-based chemotherapy, erlotinib conferred a survival benefit when compared to docetaxel ( $p=0.024$; hazard ratio, 0.377$)$. The cell growth assay confirmed that treatment with pemetrexed followed by erlotinib significantly inhibited proliferation of NSCLC cells regardless of EGFR mutation status. In conclusion, use of erlotinib at the time of progression after pemetrexed therapy confers a survival benefit in NSCLC patients with wildtype EGFR. The result of this study provides an important clue to the optimal treatment schedule for NSCLC.
\end{abstract}

Key words: erlotinib, non-small cell lung cancer, pemetrexed, survival benefit, treatment schedule, wild-type EGFR

Lung cancer is the leading cause of cancer death worldwide. Approximately $80 \%$ of lung cancer consists of non-small cell lung cancer (NSCLC), more than three-quarters of which is diagnosed at an advanced stage [1]. Drug therapy, the standard of care for advanced lung cancer, is determined according to the molecular profile of the tumor. At present, epidermal growth factor receptor (EGFR)-tyrosine kinase inhibitors (TKIs) and anaplastic lymphoma kinase (ALK)TKIs are preferentially used for NSCLC with mutant EGFR and $A L K$ rearrangements, respectively. However, more than half of NSCLC with negative or unknown oncogenic drivers require cytotoxic chemotherapy. Based on the guidelines of the American Society of Clinical Oncology (ASCO) and the National Comprehensive Cancer Network (NCCN), platinum-based doublets are recognized as the standard first-line chemotherapy for these patients, and monotherapy with docetaxel, pemetrexed, or erlotinib is proposed as the standard second-line treatment for patients in whom the first-line chemotherapy is ineffective [2]. In fact, studies have demonstrated that the efficacy was similar when comparing each of these first-line chemotherapies with platinum plus third-generation cytotoxic drugs $[3,4]$, and there were no significant differences in the therapeutic effects of docetaxel, pemetrexed, and erlotinib in patients with previously treated NSCLC [5-8]. In clinical practice, these therapies are currently used in order, and further treatment is sometimes implemented according to patient preference, as the effectiveness of pemetrexed in treatment beyond second-line chemotherapy has been reported $[9,10]$. On the other hand, accumulating evidence shows that treatment schedule of anti-tumor drugs against NSCLC may have an impact on the therapeutic effect [10-14]. A comprehensive survey of drug use throughout 
a treatment course is therefore required to assess the survival benefit for patients with NSCLC in clinical practice.

Of the third-generation cytotoxic drugs, pemetrexed is a multi-targeted anti-folate that inhibits thymidylate synthase, dihydrofolate reductase, and glycinamide ribonucleotide formyltransferase [15]. Previous phase III trials showed that pemetrexed-based chemotherapy provided favorable outcomes in NSCLC, especially for those with the non-squamous cell type, in response to the use of pemetrexed as first- and second-line treatments $[4,5]$. Based on clinical evidence, pemetrexed is currently one of the most commonly used drugs against advanced NSCLC. However, there is very limited information about the optimal use including a treatment schedule for pemetrexed. Along with concerns regarding the cost of pemetrexed $[16,17]$, determination of an optimal treatment strategy for pemetrexed may help improve therapeutic outcomes as well as the cost-effectiveness of pemetrexed therapy, leading to advances in management for NSCLC. Parameters that remain to be determined in this regard include identification of prognostic markers and determination of which drug is the optimal partner to pemetrexed.

To address these issues, we conducted a retrospective analysis of 130 patients with wild-type EGFR among 201 NSCLC patients who had undergone pemetrexed-based chemotherapies, and then used in vitro studies to confirm the clinical results. The present study advocates a specific treatment model in NSCLC patients with wild-type EGFR who are treated with pemetrexed according to practical use, and warrant further prospective studies.

\section{Patients and methods}

Study population. This study enrolled 201 patients with advanced NSCLC who were treated with pemetrexed-based chemotherapies at the Saitama Medical University International Medical Center from 2009 to 2010. Of these patients, 130 patients (65\%) who had wild-type EGFR were subjected to the analysis. The presence of EGFR mutations was examined using the peptide nucleic acid-locked nucleic acid polymerase chain reaction clamp method [18]. The medical records of these patients were retrospectively analyzed after approval of the institutional review board.

Treatment schedules. All patients were treated with pemetrexed, carboplatin/pemetrexed, cisplatin/pemetrexed, or carboplatin/pemetrexed/bevacizumab. Pemetrexed was administered as $500 \mathrm{mg} / \mathrm{m}^{2}$ every 3 weeks in each regimen, and dose reduction or cessation of the treatment was decided by attending physicians based on the onset of adverse events and disease progression. Maintenance pemetrexed monotherapy was employed for patients eligible after more than four courses of combination chemotherapies with platinum. Treatments administered just before and after treatment regimens including pemetrexed were investigated to evaluate the impact of the treatment schedule. These treatments consisted of one or more of the following drugs: cisplatin, carboplatin, paclitaxel, docetaxel, gemcitabine, vinorelbine, bevacizumab, tegafur/ gimeracil/oteracil potassium (S1), gefitinib, and erlotinib.

Clinicopathological characteristics. Patients were classified into two groups according to age ( $\geq 70$ years, $<70$ years). Performance status was assessed by the criteria of Eastern Cooperative Oncology Group (ECOG). Smoking status was classified into a "never smoker" group and a smoker group; the latter group was further divided into a light smoker group (0-20 pack-year) and a heavy smoker group ( $>20$ pack-year). Using the Response Evaluation Criteria in Solid Tumors (RECIST guideline version 1.1), maximal effects were classified into complete response (CR), partial response $(\mathrm{PR})$, stable disease $(\mathrm{SD})$, and progressive disease $(\mathrm{PD})$ [19]. $C R+P R$ was defined as objective response (OR), and $\mathrm{CR}+\mathrm{PR}+\mathrm{SD}$ was defined as disease control (DC). Parameters evaluated included the objective response rate (ORR), the disease control rate (DCR), and the time from the initiation of the corresponding treatment to the confirmation of disease progression (progression-free survival; PFS) or to death of the patient (overall survival; OS). Adverse events were evaluated according to the Common Terminology Criteria for Adverse Events version 4.0 (CTCAE v4.0).

Cell cultures. Lung cancer cell lines were obtained from the sources as follows: A549 cells (adenocarcinoma without EGFR mutations) were obtained from the Cell Resource Center for Biomedical Research, Tohoku University (Miyagi, Japan); PC9 cells (adenocarcinoma with delE746-A750 activating EGFR mutation) were purchased from Immuno-Biological Laboratories (Gunma, Japan); and NCI-H1975 cells (adenocarcinoma with both L858R activating and T790M resistant EGFR mutations) were purchased from the American Type Culture Collection (Manassas, VA, USA). Cells were grown in Dulbecco's Modified Eagle's Medium (DMEM) (Sigma, St. Louis, MO, USA) supplemented with $10 \%$ fetal bovine serum (FBS) (Gibco, Grand Island, NY, USA) in a humidified chamber with air containing $5 \% \mathrm{CO}_{2}$.

Cytotoxic assay. The cytotoxic activity of each drug was evaluated using the Cell Counting Kit-8 (CCK-8) (Dojindo, Kumamoto, Japan). According to the manufacturer's instructions, each cell type was seeded into 96-well dishes at $0.3 \times$ $10^{4}$ cells/well. After incubation for $24 \mathrm{~h}$, cells were treated with each drug for $72 \mathrm{~h}$. Thereafter, $10 \mu \mathrm{L}$ of CCK- 8 was added to each well, followed by further incubation for $1.5-2 \mathrm{~h}$ at $37^{\circ} \mathrm{C}$. The optimal density of each well was measured at $450 \mathrm{~nm}$ on a 1420 multilabel counter ARVO MX (PerkinElmer, Waltham, MA, USA). The cell-growth inhibitory rate was expressed as the percentage of cell viability calculated as follows: [(mean absorbance of drug-treated wells minus mean absorbance of blank wells)/(mean absorbance of control wells minus mean absorbance of blank wells) $] \times 100$. $\mathrm{IC}_{50}$ was defined as the drug concentration that induced $50 \%$ of growth inhibition.

In vitro cell growth assay. To evaluate the in vitro therapeutic efficacy of drugs administered before and after pemetrexed, three types of NSCLC cell lines were treated with candidate drugs before and after pemetrexed treatment. According to 
the conditions in the previous reports regarding treatment schedule $[20,21]$, each cell type was treated with medium containing the $\mathrm{IC}_{50}$ concentration of pemetrexed disodium (Toronto Research Chemicals, Ontario, Canada) for $72 \mathrm{~h}$, washed and incubated in medium without anti-tumor drugs for $72 \mathrm{~h}$, and then treated with medium containing the $\mathrm{IC}_{50}$ concentration of candidate drugs for $72 \mathrm{~h}$. The reverse treatment schedule was applied to the assay of drug use followed by pemetrexed. Next, $10 \mu \mathrm{L}$ of CCK- 8 was added to each well, which was further incubated for $1.5-2 \mathrm{~h}$ at $37^{\circ} \mathrm{C}$. Then, the optimal density of each well was measured at $450 \mathrm{~nm}$, and the cell-growth inhibitory rate was expressed as the percentage of cell viability, as described above. Each experiment was performed independently and in triplicate.

Statistical analysis. PFS and OS for each parameter were calculated using the Kaplan-Meier method, and the log-rank test was used to compare groups. Multivariate logistic regression analysis was used to adjust for potential confounding factors. Differences in the cell growth assay were assessed by the Mann-Whitney $U$ test. A $p$ value of $<0.05$ was considered to represent statistical significance.

Table 1. Characteristics of patients who received pemetrexed-based chemotherapy $(n=130)$

\begin{tabular}{|c|c|c|}
\hline \multicolumn{2}{|l|}{ Parameters } & No. of Patients \\
\hline \multicolumn{3}{|l|}{ Age } \\
\hline \multirow[t]{3}{*}{ Median (range) } & & $66(37-82)$ \\
\hline & $<70$ & 93 \\
\hline & $\geq 70$ & 37 \\
\hline \multicolumn{3}{|l|}{ Sex } \\
\hline \multicolumn{2}{|l|}{ Male } & 90 \\
\hline \multicolumn{2}{|l|}{ Female } & 40 \\
\hline \multicolumn{3}{|c|}{ Performance status (ECOG) } \\
\hline \multicolumn{2}{|l|}{0} & 73 \\
\hline \multicolumn{2}{|l|}{1} & 41 \\
\hline \multicolumn{2}{|l|}{2} & 10 \\
\hline \multicolumn{2}{|l|}{3} & 6 \\
\hline \multicolumn{3}{|l|}{ Smoking history } \\
\hline \multicolumn{2}{|l|}{ Never smoker } & 35 \\
\hline \multicolumn{2}{|r|}{$($ Pack year $\leq 20)$} & 8 \\
\hline Heavy smoker & $($ Pack year $>20)$ & 87 \\
\hline \multicolumn{3}{|l|}{ Histological type } \\
\hline \multicolumn{2}{|l|}{ Adenocarcinoma } & 115 \\
\hline \multicolumn{2}{|c|}{ Squamous cell carcinoma } & 2 \\
\hline \multicolumn{2}{|c|}{ Large cell carcinoma } & 3 \\
\hline \multicolumn{2}{|c|}{ Adenosquamous carcinoma } & 1 \\
\hline \multicolumn{2}{|c|}{ Large cell neuroendocrine carcinoma } & 1 \\
\hline \multicolumn{2}{|c|}{ Pleomorphic carcinoma } & 1 \\
\hline \multicolumn{2}{|c|}{ Diagnosed only as NSCLC } & 7 \\
\hline \multicolumn{3}{|l|}{ Clinical stage } \\
\hline \multicolumn{2}{|l|}{ IIIB } & 9 \\
\hline \multicolumn{2}{|l|}{ IV } & 121 \\
\hline
\end{tabular}

ECOG, eastern cooperative oncology group; NSCLC, non-small cell lung cancer

\section{Results}

Patient characteristics. The clinicopathological characteristics of 130 NSCLC patients with wild-type EGFR who received pemetrexed-based chemotherapy are shown in Table 1. Most patients had good performance status, adenocarcinoma, and stage IV.

Treatment regimen and schedule. Treatment regimens and schedules used for pemetrexed-based chemotherapy are shown in Table 2. Thirty-two of 81 patients who received combination chemotherapies with platinum and pemetrexed (40\%) underwent maintenance treatment with pemetrexed. Furthermore, $48 \%$ of 130 patients received subsequent

Table 2. Treatment history and regimen

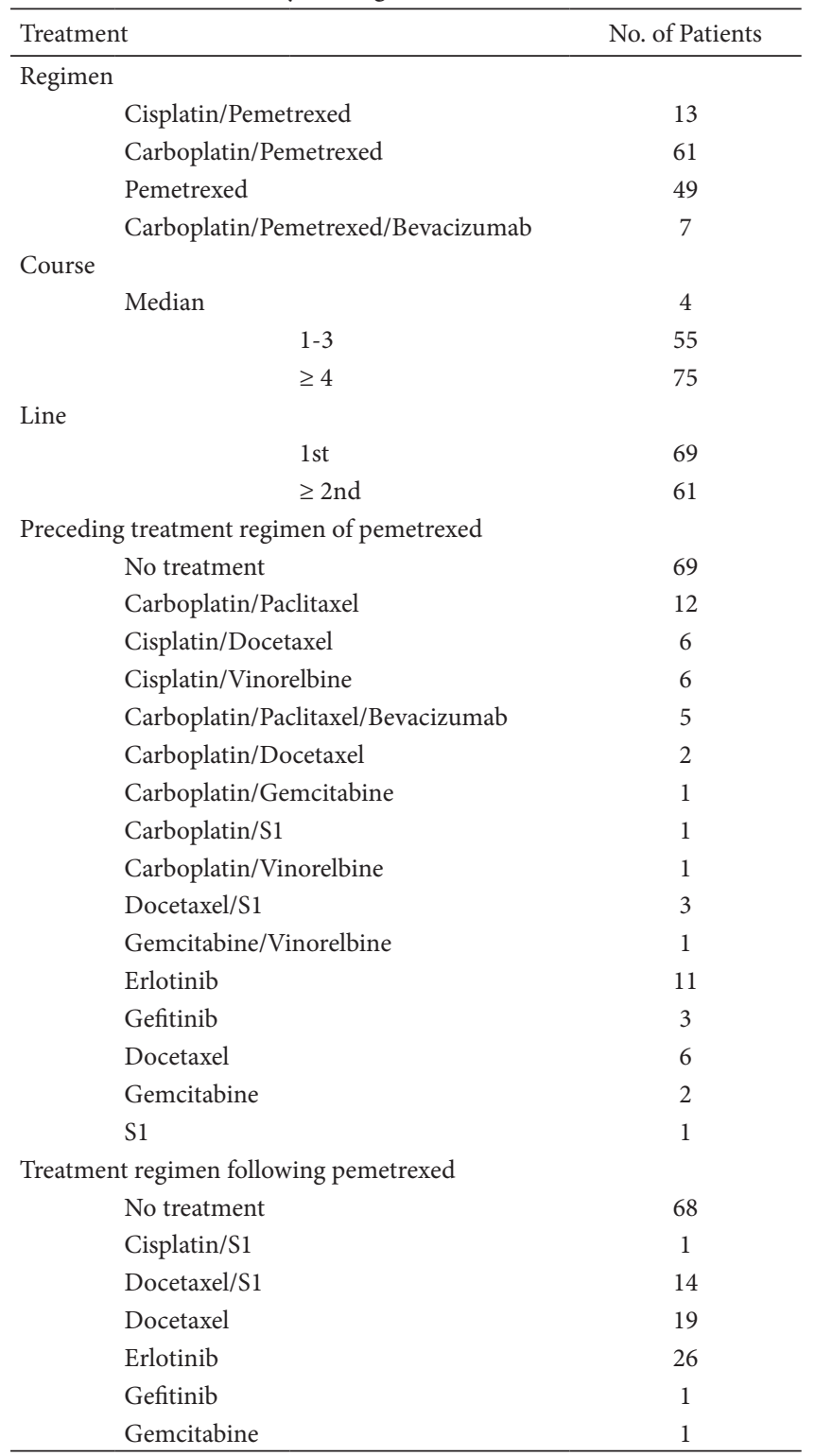

S1, Tegafur/gimeracil/oteracil potassium 
treatment with other drugs after failure of pemetrexed. Of treatment regimens just after pemetrexed, docetaxel-based chemotherapy including docetaxel monotherapy (15\%) and docetaxel/S1 (11\%) was most frequently employed. As a monotherapy, erlotinib (20\%) was most frequently employed. The median elapsed time from the preceding pemetrexed-based chemotherapy to erlotinib and docetaxel in this clinical analysis were 13 and 19 days, respectively. Compared to pemetrexed monotherapy, platinum-combined pemetrexed chemotherapy elicited favorable therapeutic responses, whereas there were no significant differences in survival between both therapy types as shown in Table 3; these data are comparable to those from previous reports $[4,5]$. There were no fatal toxicities, while the occurrence of grade 3-4 toxicities as follows: nephrotoxicity $(0.7 \%)$, anorexia $(0.7 \%)$, neutropenia (19.2\%), anemia (11.5\%), and thrombocytopenia (15.4\%) for grade 3; neutropenia (3.1\%) and thrombocytopenia (0.7\%) for grade 4.

Analysis of survival benefit. Kaplan-Meier survival curves and log-rank tests showed that the following factors had a significant effect on survival: maintenance treatment, performance status, ORR, and DCR for PFS for pemetrexedbased therapy; and DCR, treatment course, pemetrexed monotherapy, and performance status for OS for pemetrexedbased therapy. These survival analyses were also applied for the treatment schedule employed in this study as follows: erlotinib, docetaxel, carboplatin/paclitaxel, cisplatin-based chemotherapy, or carboplatin-based chemotherapy as treatment before pemetrexed; and erlotinib, gefitinib, and docetaxel-based chemotherapy as treatment after pemetrexed. None of the drugs used before treatment with pemetrexedbased chemotherapy were associated with significant OS benefit. Of treatments initiated at the time of progression after pemetrexed-based chemotherapy, erlotinib monotherapy that was independently associated with significant OS benefit (Figure 1A) produced the same result even after pemetrexed monotherapy (Figure 1B). On the other hand, there were no statistical differences in PFS for only preceding pemetrexed-based chemotherapy between erlotinib-treated patients and others (data not shown). Of interest, erlotinib
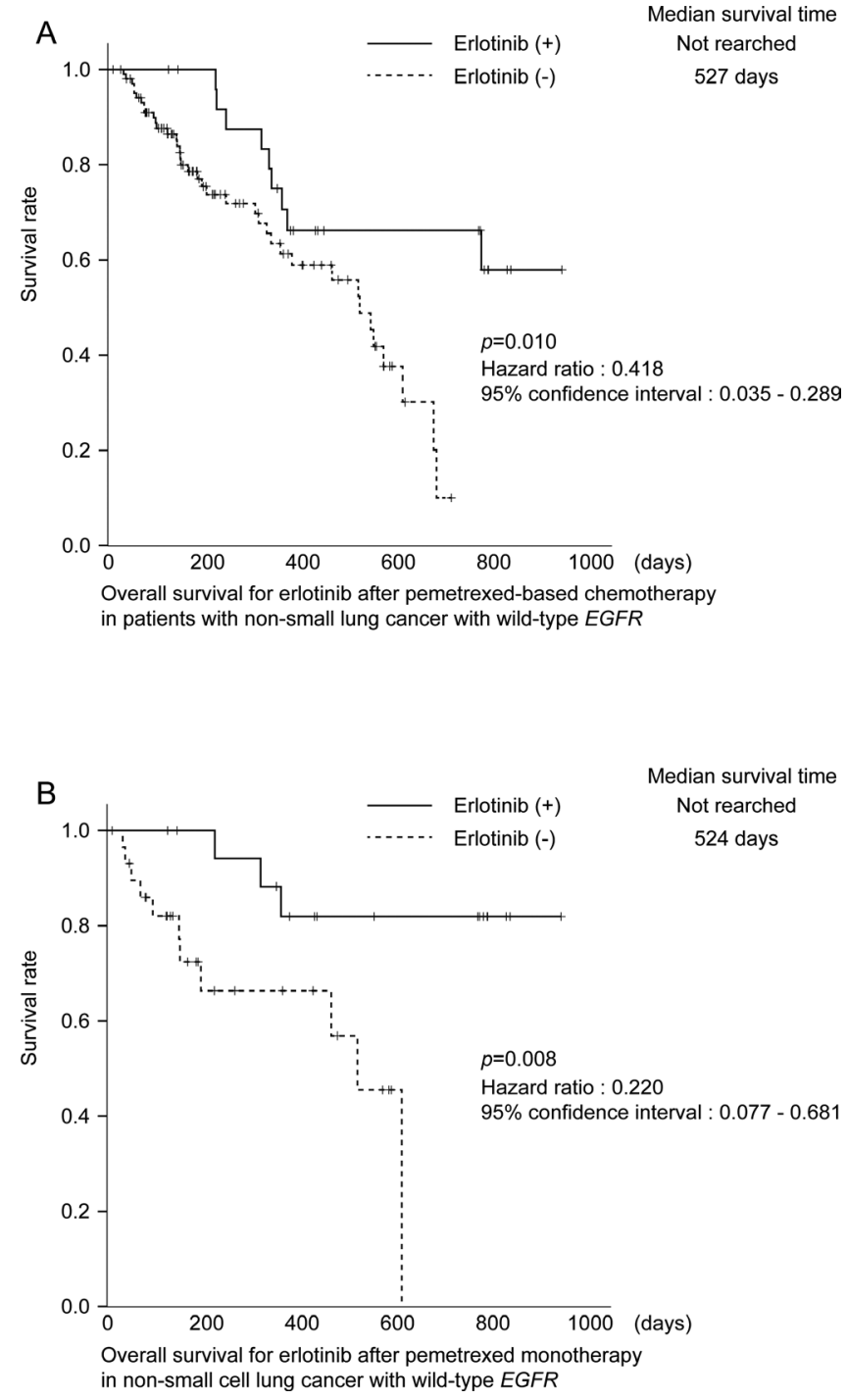

Figure 1. Kaplan-Meier survival curves with log-rank tests for treatment with erlotinib after pemetrexed. Erlotinib at the time of progression after pemetrexed-based chemotherapy (A) and pemetrexed monotherapy (B) significantly prolonged overall survival in non-small cell lung cancer with wild-type EGFR.

Table 3. Therapeutic response and survival time according to therapeutic regimens

\begin{tabular}{|c|c|c|c|c|c|c|c|c|}
\hline \multirow[t]{2}{*}{ Treatment regimen } & \multicolumn{4}{|c|}{ Therapeutic response (number) } & \multirow{2}{*}{ ORR (\%) } & \multirow{2}{*}{$\operatorname{DCR}(\%)$} & \multirow{2}{*}{$\begin{array}{c}\text { PFS } \\
\text { (days }[95 \% \mathrm{CI}] \text { ) }\end{array}$} & \multirow{2}{*}{$\begin{array}{c}\text { OS } \\
\text { (days }[95 \% \mathrm{CI}] \text { ) }\end{array}$} \\
\hline & $\mathrm{CR}$ & PR & SD & $\mathrm{PD}$ & & & & \\
\hline Total $(n=130)$ & 3 & 27 & 60 & 40 & 23 & 69 & $133[114-152]$ & $556[462-650]$ \\
\hline Platinum-combined therapy (81) & 3 & 23 & 35 & 20 & 32 & 75 & $150[121-179]$ & $527[320-734]$ \\
\hline Cisplatin/Pemetrexed (13) & 2 & 2 & 7 & 2 & 31 & 85 & 226 [103-349] & $375[155-606]$ \\
\hline Carboplatin/Pemetrexed (61) & 0 & 17 & 26 & 18 & 28 & 70 & $131[115-147]$ & $550[305-795]$ \\
\hline Carboplatin/Pemetrexed/Bevacizumab (7) & 1 & 4 & 2 & 0 & 71 & 100 & 213 [129-297] & $341[208-474]$ \\
\hline Pemetrexed (49) & 0 & 4 & 25 & 20 & 8 & 59 & 124 [ 71-177] & NR \\
\hline
\end{tabular}

CR, complete response; PR, partial response; SD, stable disease; PD, progressive disease; ORR, objective response rate; DCR, disease control rate; PFS, progression-free survival; OS, overall survival, NR; not reached 
monotherapy at the time of progression after pemetrexedbased chemotherapy resulted in better PFS and OS even when compared to docetaxel-based chemotherapy as well as docetaxel monotherapy (Figure 2). Similar analyses in pemetrexed monotherapy were not applied because of only 3 patients who had received docetaxel monotherapy after pemetrexed monotherapy. Multivariate logistic regression analysis revealed that the use of erlotinib monotherapy after pemetrexed was associated with smoking status (neversmoker), treatment course (more than four courses), and OR in pemetrexed (Table 4), whereas no parameters other than treatment course that showed a negative association provided a survival benefit (data not shown).

In vitro evaluation of erlotinib efficacy after pemetrexed. The in vitro cell growth assay was used to evaluate erlotinib efficacy after treatment with pemetrexed. To clarify erlotinib efficacy, the assay was also applied for docetaxel. Pemetrexed, erlotinib, or docetaxel (Focus Biomolecules, Plymouth Meeting, PA, USA) after pemetrexed treatment was administered at 72-h intervals with the $\mathrm{IC}_{50}$ concentrations for each drug in
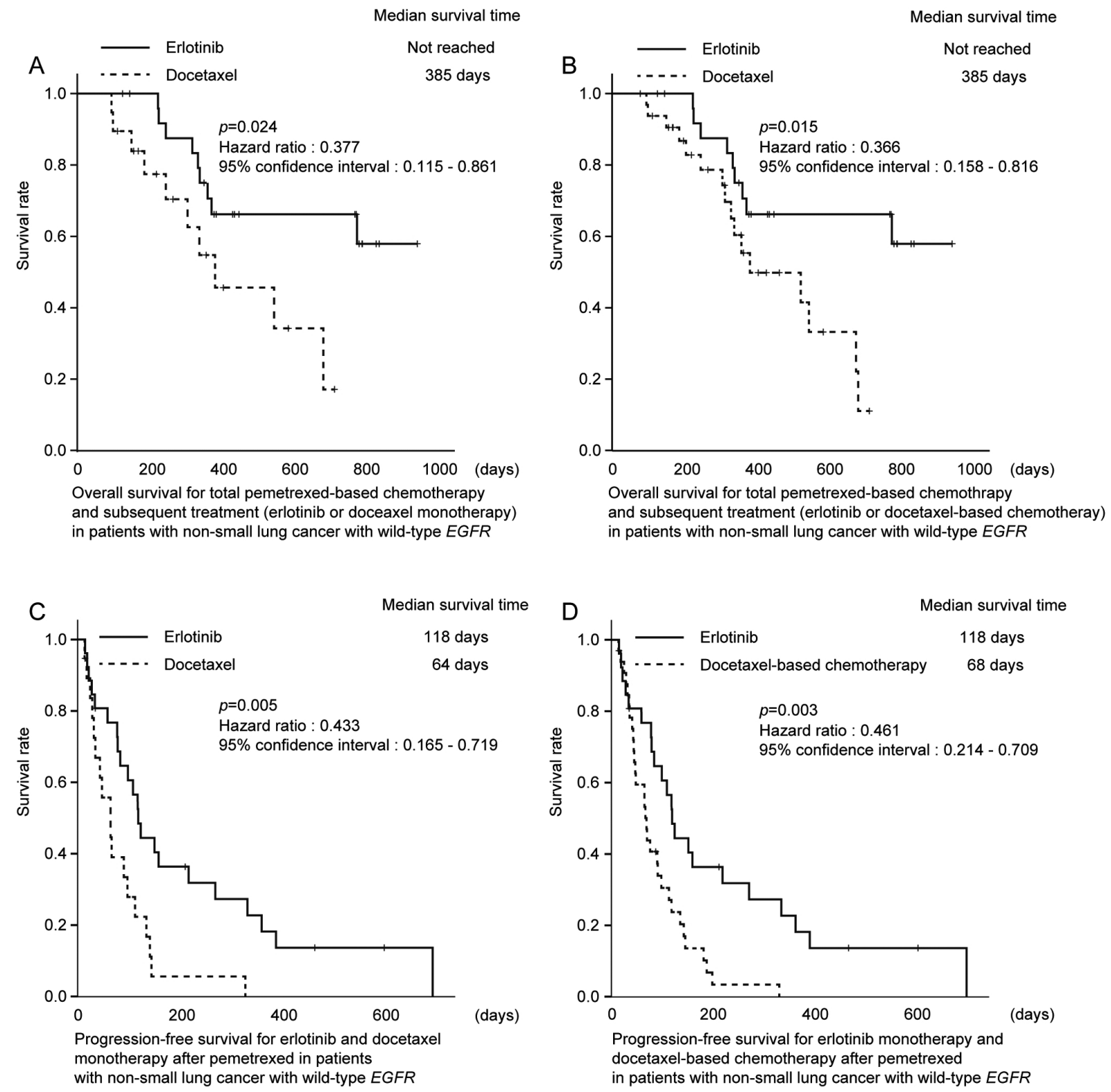

Figure 2. Kaplan-Meier survival curves with log-rank tests for treatment with erlotinib versus docetaxel at the time of progression after pemetrexedbased chemotherapy. Overall survival for total pemetrexed-based chemotherapy and subsequent erlotinib was significantly longer than that for total pemetrexed-based chemotherapy and docetaxel monotherapy (A) or docetaxel-based chemotherapy (B). Progression-free survival confined to erlotinib was also longer than docetaxel monotherapy (C) or docetaxel-based chemotherapy (D). 
individual cells (Table 5). Cells that were treated with pemetrexed again after pemetrexed exposure were used as a control group (pemetrexed $\rightarrow$ pemetrexed group; $\mathrm{P} \rightarrow \mathrm{P}$ ). The growth inhibitory rates of each treatment schedule in individual cells compared to control groups were as follows (median value \pm standard deviation): Treatment with erlotinib after pemetrexed (pemetrexed $\rightarrow$ erlotinib group; $\mathrm{P} \rightarrow \mathrm{E}$ ), $0.702 \pm 0.066$ and treatment with docetaxel after pemetrexed (pemetrexed $\rightarrow$ docetaxel group; $\mathrm{P} \rightarrow \mathrm{D}$ ), $0.931 \pm 0.267$ in A549 cells; $\mathrm{P} \rightarrow$ E, $0.581 \pm 0.141$ and $\mathrm{P} \rightarrow \mathrm{D}, 0.822 \pm 0.131$ in PC9 cells; $\mathrm{P} \rightarrow \mathrm{E}$, $0.599 \pm 0.083$ and $\mathrm{P} \rightarrow \mathrm{D}, 0.819 \pm 0.309$ in NCI-H1975 cells (Figure 3 ). The pemetrexed $\rightarrow$ erlotinib group resulted in significant growth inhibition of all types of cells when compared to the pemetrexed $\rightarrow$ docetaxel group and the control group. There were no significant differences in the growth inhibitory rate in the reverse schedules, respectively.

\section{Discussion}

The present study provided both clinical and biological evidence that erlotinib at the time of progression after pemetrexed therapy prolonged survival in NSCLC patients with wild-type EGFR. The previous retrospective study reported the superiority of the reverse treatment sequence [22]. However, previous in vitro studies show that EGFR/Akt phosphorylation, low thymidylate synthase (TS) expression, and cell cycle-dependent cytotoxicity mediate the synergistic effect of pemetrexed and subsequent erlotinib [20, 21,
23-26]. These findings may account for a direct molecular mechanism underlying favorable outcome from treatment sequence of erlotinib after pemetrexed regardless of EGFR mutation status. Along with such evidences, our biological data exemplify the survival benefit from the treatment schedule of erlotinib following pemetrexed compared to the reverse treatment sequence.

While these reports regarding treatment sequences, there is very limited information about which partner for pemetrexed as a treatment schedule is optimal. In this context, erlotinib also conferred a survival advantage compared to docetaxel, when used as treatment after pemetrexed. Some recent trials for previously treated NSCLC with wild-type EGFR suggested superior outcomes of docetaxel over erlotinib $[27,28]$, others reported that the effect of EGFR-TKIs is equivalent to that of docetaxel $[6,8]$. Different drugs had been administered before docetaxel or erlotinib in these trials, whereas patients who received the preceding pemetrexed therapy have been exclusively the subject of the present study. This focused approach may sensitively reflect the effectiveness of the treatment schedule for pemetrexed compared to the previous trials. One of other potential explanations for our results is that erlotinib may be better tolerated than the cytotoxic drugs, leading to long-term administration $[8,29,30]$. Since more emphasis has been placed on palliative than curative intent when using treatment after first-line chemotherapy [31], preferred reduced toxicity in treatment may have induced early termination of the cytotoxic drugs which had a similar toxicity profile to

Table 4. Logistic regression analysis for erlotinib monotherapy following pemetrexed

\begin{tabular}{lccc}
\hline & Odds ratio & 95\% Confidence interval & $p$-Value \\
\hline Age $(70>$ ) & 1.808 & $0.463-7.050$ & 0.394 \\
Smoking status (20 pack/year $>$ ) & 0.082 & $0.018-0.374$ & 0.001 \\
Sex (Female) & 1.460 & $0.319-6.674$ & 0.626 \\
Histology (Adenocarcinoma) & 0.627 & $0.117-3.368$ & 0.587 \\
Treatment course of pemetrexed (Four $\geq)$ & 8.157 & $1.718-38.723$ & 0.008 \\
Treatment line of pemetrexed (1st line) & 0.232 & $0.052-1.031$ & 0.055 \\
Performance status (0-1) & 3.707 & $0.872-15.754$ & 0.076 \\
Objective response of pemetrexed (CR+PR) & 0.115 & $0.017-0.759$ & 0.025 \\
Disease control of pemetrexed (CR+PR+SD) & 0.721 & $0.157-3.303$ & 0.674 \\
Maintenance treatment (+) & 1.229 & $0.243-6.217$ & 0.804 \\
\hline
\end{tabular}

CR, complete response; PR, partial response; SD, stable disease

Table 5. IC50 for each drug in individual cell lines $(\mu \mathrm{M})$

\begin{tabular}{lccc}
\hline \multicolumn{1}{c}{ Cell type } & \multicolumn{2}{c}{ Drug } \\
\cline { 2 - 4 } & Pemetrexed & Erlotinib & Docetaxel \\
\hline A549 (wild-type EGFR) & 1.0 & 1.7 & 0.006 \\
PC9 (delE746-A750 activating EGFR mutation) & 0.25 & 0.5 & 0.003 \\
NCI-H1975 (L858R activating and T790M resistant EGFR mutations) & 10.0 & 10.0 & 0.002 \\
\hline
\end{tabular}



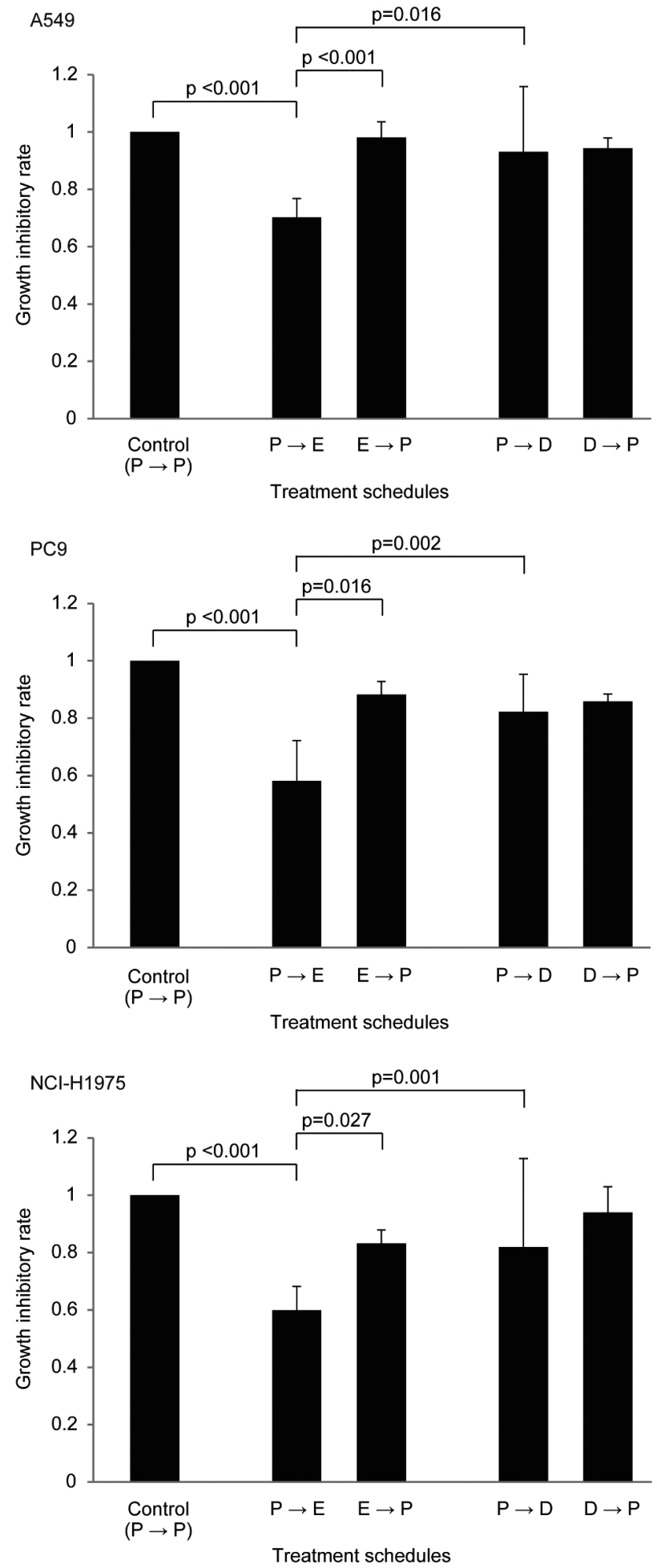

Figure 3. The in vitro cell growth assays for treatment schedules of pemetrexed $\rightarrow$ pemetrexed $(\mathrm{P} \rightarrow \mathrm{P}$; control), pemetrexed $\rightarrow$ erlotinib $(\mathrm{P} \rightarrow$ E), erlotinib $\rightarrow$ pemetrexed $(E \rightarrow P)$, pemetrexed $\rightarrow$ docetaxel $(P \rightarrow D)$, and docetaxel $\rightarrow$ pemetrexed $(\mathrm{D} \rightarrow \mathrm{P})$ using three types of NSCLC cell lines, A549 (wild-type EGFR), PC9 (delE746-A750 activating EGFR mutation), and NCI-H1975 cells (both L858R activating and T790M resistant EGFR mutations). Data represent median values \pm standard deviations. pemetrexed. The choice of EGFR-TKI after a cytotoxic drug may improve clinical outcome.

On the other hand, one limitation of the present study is that reciprocal treatment sequences of pemetrexed and erlotinib were not directly compared. As another limitation, the present study consists of a heterogenous population including patients who had received the different preceding treatments and were treated with pemetrexed at different treatment-lines. However, neither preceding treatments nor treatment-lines were associated with a survival benefit of pemetrexed therapy. Furthermore, no drugs other than erlotinib provided a survival benefit as the treatment following pemetrexed. Multivariate analysis also showed that no potential confounding factors positively affects erlotinib therapy.

In conclusion, use of erlotinib at the time of progression after pemetrexed therapy confers a survival benefit in NSCLC patients with wild-type EGFR. Our findings provide an important clue to accessing the significance of the treatment schedule and advocate the possibility of a novel therapeutic approach, although further validation requires large-scale prospective trials that consist of a homogenous population and minimized a potential bias.

Acknowledgements: We thank Dr. Kunihiko Kobayashi for general support and Dr. Naoko Wada for technical support. Erlotinib was kindly gifted from F. Hoffman La Roche (Basel, Switzerland).

\section{References}

[1] JEMAL A, SIEGEL R, WARD E, HAO Y, XU J et al. Cancer statistics, 2008. CA Cancer J Clin 2008; 58: 71-96. http:// dx.doi.org/10.3322/CA.2007.0010

[2] AZZOLI CG, BAKER S, JR., TEMIN S, PAO W, ALIFF T et al. American Society of Clinical Oncology Clinical Practice Guideline update on chemotherapy for stage IV non-smallcell lung cancer. J Clin Oncol 2009; 27: 6251-66. http://dx.doi. org/10.1200/JCO.2009.23.5622

[3] SCHILLER JH, HARRINGTON D, BELANI CP, LANGER C, SANDLER A et al. Comparison of four chemotherapy regimens for advanced non-small-cell lung cancer. N Engl J Med 2002; 346: 92-8. http://dx.doi.org/10.1056/NEJMoa011954

[4] SCAGLIOTTI GV, PARIKH P, VON PAWEL J, BIESMA B, VANSTEENKISTE J et al. Phase III study comparing cisplatin plus gemcitabine with cisplatin plus pemetrexed in chemotherapy-naive patients with advanced-stage non-smallcell lung cancer. J Clin Oncol 2008; 26: 3543-51. http://dx.doi. org/10.1200/JCO.2007.15.0375

[5] HANNA N, SHEPHERD FA, FOSSELLA FV, PEREIRA JR, DE MARINIS $F$ et al. Randomized phase III trial of pemetrexed versus docetaxel in patients with non-small-cell lung cancer previously treated with chemotherapy. J Clin Oncol 2004; 22: 1589-97. http://dx.doi.org/10.1200/JCO.2004.08.163

[6] NG R, LORETO M, LEE R, LEIGHL NB. Brief report: retrospective review of efficacy of erlotinib or gefitinib compared to docetaxel as subsequent line therapy in advanced non-small cell lung cancer (NSCLC) following failure of platinum-based 
chemotherapy. Lung Cancer 2008; 61: 262-5. http://dx.doi. org/10.1016/j.lungcan.2008.02.002

[7] POPAT S, BARBACHANO Y, ASHLEY S, NORTON A, O'BRIEN M. Erlotinib, docetaxel, and gefitinib in sequential cohorts with relapsed non-small cell lung cancer. Lung Cancer 2008; 59: 227-31. http://dx.doi.org/10.1016/j. lungcan.2007.08.027

[8] CIULEANU T, STELMAKH L, CICENAS S, MILIAUSKAS S, GRIGORESCU AC et al. Efficacy and safety of erlotinib versus chemotherapy in second-line treatment of patients with advanced, non-small-cell lung cancer with poor prognosis (TITAN): a randomised multicentre, open-label, phase 3 study. Lancet Oncol 2012; 13: 300-8. http://dx.doi.org/10.1016/ $\underline{\mathrm{S} 1470-2045(11) 70385-0}$

[9] MURILLO JR, JR., KOELLER J. Chemotherapy given near the end of life by community oncologists for advanced non-small cell lung cancer. Oncologist 2006; 11: 1095-9. http://dx.doi. org/10.1634/theoncologist.11-10-1095

[10] CHANG MH, AHN JS, LEE J, KIM KH, PARK YH et al. The efficacy of pemetrexed as a third- or fourth-line therapy and the significance of thymidylate synthase expression in patients with advanced non-small cell lung cancer. Lung Cancer 2010; 69: 323-9. http://dx.doi.org/10.1016/j.lungcan.2009.12.002

[11] MANEGOLD C, PILZ LR, KOSCHEL G, ROMER KS, MEZGER J et al. Randomized multicenter phase II study of gemcitabine versus docetaxel as first-line therapy with secondline crossover in advanced-stage non-small-cell lung cancer. Clin Lung Cancer 2005; 7: 208-14. http://dx.doi.org/10.3816/ CLC.2005.n.038

[12] GRIDELLI C, KAUKEL E, GREGORC V, MIGLIORINO MR, MULLER TR et al. Single-agent pemetrexed or sequential pemetrexed/gemcitabine as front-line treatment of advanced non-small cell lung cancer in elderly patients or patients ineligible for platinum-based chemotherapy: a multicenter, randomized, phase II trial. J Thorac Oncol 2007; 2: 221-9. http://dx.doi.org/10.1097/JTO.0b013e318031cd62

[13] PEROL M, CHOUAID C, PEROL D, BARLESI F, GERVAIS R et al. Randomized, phase III study of gemcitabine or erlotinib maintenance therapy versus observation, with predefined second-line treatment, after cisplatin-gemcitabine induction chemotherapy in advanced non-small-cell lung cancer. J Clin Oncol 2012; 30: 3516-24. http://dx.doi.org/10.1200/ JCO.2011.39.9782

[14] GRIDELLI C, CIARDIELLO F, GALLO C, FELD R, BUTTS $\mathrm{C}$ et al. First-line erlotinib followed by second-line cisplatingemcitabine chemotherapy in advanced non-small-cell lung cancer: the TORCH randomized trial. J Clin Oncol 2012; 30: 3002-11. http://dx.doi.org/10.1200/JCO.2011.41.2056

[15] SHIH C, CHEN VJ, GOSSETT LS, GATES SB, MACKELLAR WC et al. LY231514, a pyrrolo[2,3-d]pyrimidine-based antifolate that inhibits multiple folate-requiring enzymes. Cancer Res 1997; 57: 1116-23.

[16] GIULIANI G, GROSSI F, DE MARINIS F, WALZER S. Costeffectiveness analysis of bevacizumab versus pemetrexed for advanced non-squamous NSCLC in Italy. Lung Cancer 2010; 69 Suppl 1: S11-7. http://dx.doi.org/10.1016/S0169-5002(10)70133-1
[17] NADLER E, FORSYTH M, SATRAM-HOANG S, REYES C. Costs and clinical outcomes among patients with second-line non-small cell lung cancer in the outpatient community setting. J Thorac Oncol 2012; 7: 212-8. http://dx.doi.org/10.1097/ ITO.0b013e3182307f33

[18] NAGAI Y, MIYAZAWA H, HUQUN, TANAKA T, UDAGAWA K et al. Genetic heterogeneity of the epidermal growth factor receptor in non-small cell lung cancer cell lines revealed by a rapid and sensitive detection system, the peptide nucleic acid-locked nucleic acid PCR clamp. Cancer Res 2005; 65: 7276-82. http://dx.doi.org/10.1158/0008-5472.CAN-05$\underline{0331}$

[19] THERASSE P, ARBUCK SG, EISENHAUER EA, WANDERS J, KAPLAN RS et al. New guidelines to evaluate the response to treatment in solid tumors. European Organization for Research and Treatment of Cancer, National Cancer Institute of the United States, National Cancer Institute of Canada. J Natl Cancer Inst 2000; 92: 205-16. http://dx.doi.org/10.1093/ inci/92.3.205

[20] GIOVANNETTIE, LEMOS C, TEKLE C, SMID K, NANNIZZI $S$ et al. Molecular mechanisms underlying the synergistic interaction of erlotinib, an epidermal growth factor receptor tyrosine kinase inhibitor, with the multitargeted antifolate pemetrexed in non-small-cell lung cancer cells. Mol Pharmacol 2008; 73: 1290-300. http://dx.doi.org/10.1124/mol.107.042382

[21] LI T, LING YH, GOLDMAN ID, PEREZ-SOLER R. Scheduledependent cytotoxic synergism of pemetrexed and erlotinib in human non-small cell lung cancer cells. Clin Cancer Res 2007; 13: 3413-22. http://dx.doi.org/10.1158/1078-0432.CCR06-2923

[22] FIALA O, PESEK M, FINEK J, BENESOVA L, BORTLICEK $\mathrm{Z}$ et al. Sequential treatment of advanced-stage lung adenocarcinoma harboring wild-type EGFR gene: second-line pemetrexed followed by third-line erlotinib versus the reverse sequence. Anticancer Res 2013; 33: 3397-402.

[23] TAKEZAWA K, OKAMOTO I, OKAMOTO W, TAKEDA $\mathrm{M}$, SAKAI $\mathrm{K}$ et al. Thymidylate synthase as a determinant of pemetrexed sensitivity in non-small cell lung cancer. $\mathrm{Br}$ J Cancer 2011; 104: 1594-601. http://dx.doi.org/10.1038/ bjc. 2011.129

[24] SUN JM, HAN J, AHN JS, PARK K, AHN MJ. Significance of thymidylate synthase and thyroid transcription factor 1 expression in patients with nonsquamous non-small cell lung cancer treated with pemetrexed-based chemotherapy. J Thorac Oncol 2011; 6: 1392-9. http://dx.doi.org/10.1097/ ITO.0b013e3182208ea8

[25] CHEN CY, CHANG YL, SHIH JY, LIN JW, CHEN KY et al. Thymidylate synthase and dihydrofolate reductase expression in non-small cell lung carcinoma: the association with treatment efficacy of pemetrexed. Lung Cancer 2011; 74: 132-8. http://dx.doi.org/10.1016/j.lungcan.2011.01.024

[26] WANG L, ZHU ZX, ZHANG WY, ZHANG WM. Scheduledependent cytotoxic synergism of pemetrexed and erlotinib in BXPC-3 and PANC-1 human pancreatic cancer cells. Exp Ther Med 2011; 2: 969-975.

[27] GARASSINO MC, MARTELLI O, BROGGINI M, FARINA G, VERONESE $S$ et al. Erlotinib versus docetaxel as second- 
line treatment of patients with advanced non-small-cell lung cancer and wild-type EGFR tumours (TAILOR): a randomised controlled trial. Lancet Oncol 2013; 14: 981-8. http://dx.doi.org/10.1016/S1470-2045(13)70310-3

[28] KAWAGUCHI T, ANDO M, ASAMI K, OKANO Y, FUKUDA $M$ et al. Randomized phase III trial of erlotinib versus docetaxel as second- or third-line therapy in patients with advanced non-small-cell lung cancer: Docetaxel and Erlotinib Lung Cancer Trial (DELTA). J Clin Oncol 2014; 32: 1902-8. http://dx.doi.org/10.1200/JCO.2013.52.4694

[29] MELOSKY B, AGULNIK J, ASSI H. Retrospective practice review of treatment of metastatic non-small-cell lung cancer with second-line erlotinib. Curr Oncol 2008; 15: 279-85. http://dx.doi.org/10.3747/co.v15i6.382
[30] QI WX, SHEN Z, LIN F, SUN YJ, MIN DL et al. Comparison of the efficacy and safety of EFGR tyrosine kinase inhibitor monotherapy with standard second-line chemotherapy in previously treated advanced non-small-cell lung cancer: a systematic review and meta-analysis. Asian Pac J Cancer Prev 2012; 13: 5177-82. http://dx.doi.org/10.7314/ APJCP.2012.13.10.5177

[31] DANCEY J, SHEPHERD FA, GRALLA RJ, KIM YS. Quality of life assessment of second-line docetaxel versus best supportive care in patients with non-small-cell lung cancer previously treated with platinum-based chemotherapy: results of a prospective, randomized phase III trial. Lung Cancer 2004; 43: 183-94. http://dx.doi.org/10.1016/j. lungcan.2003.09.001 